\title{
Improvement in Early Recovery after Endoscopic Carpal Tunnel Surgery with the NeuroGen Nerve Support Supplement
}

\author{
Michael J. Fitzmaurice \\ Fitzmaurice Hand Institute, Scottsdale, AZ, USA \\ Email: mfitz70@me.com
}

How to cite this paper: Fitzmaurice, M.J. (2022) Improvement in Early Recovery after Endoscopic Carpal Tunnel Surgery with the NeuroGen Nerve Support Supplement. Modern Plastic Surgery, 12, 13-24. https://doi.org/10.4236/mps.2022.122002

Received: December 30, 2021

Accepted: February 7, 2022

Published: February 10, 2022

Copyright ( 2022 by author(s) and Scientific Research Publishing Inc. This work is licensed under the Creative Commons Attribution International License (CC BY 4.0).

http://creativecommons.org/licenses/by/4.0/

\section{(c) (i) Open Access}

\begin{abstract}
Several papers have identified supplements that may relieve symptoms of carpal tunnel syndrome and improve recovery when carpal tunnel surgery is required. 64 patients with clinically and electromyographically confirmed carpal tunnel syndrome were enrolled in a prospective study to evaluate the effectiveness of a nerve supplement on patient rated outcome assessment after carpal tunnel surgery. All the patients underwent endoscopic carpal tunnel surgery. 18 patients also took the NeuroGen nerve supplement as part of their perioperative treatment. Both groups demonstrated a statistically significant improvement in BCTQ (both symptoms and function) at 2 weeks follow up. The supplement group demonstrated a statistically significant difference in improvement on the BCTQ (both symptoms and function) compared to the control group without the supplement. The NeuroGen nerve supplement appears to improve recovery on both the symptoms and function component of the BCTQ after endoscopic carpal tunnel surgery within 2 weeks.
\end{abstract}

\section{Keywords}

Endoscopic, ECTR, Carpal Tunnel, Nerve Supplement, Nerve, Supplement, BCTQ

\section{Introduction}

Carpal tunnel syndrome is common and often requires surgical intervention for appropriate treatment [1] [2]. Endoscopic carpal tunnel release has shown in multiple studies to provide less scar pain, more grip strength and quicker return to work activity [3]. Although the endoscopic technique has generally shown a quicker recovery our goal was to evaluate if the nerve support supplement Neu- 
roGen could further improve recovery. Several supplements have been used to treat patients with carpal tunnel syndrome. These include alpha lipoic acid, acetyl 1 carnitine, vitamin D and serratiopeptidase [4] [5] [6] [7]. Other ingredients such as alpha lipoic acid, curcumin and B vitamins have been used to help improve outcomes after surgical release of the carpal tunnel [8] [9] [10]. NeuroGen is a nerve supplement which contains ingredients that have demonstrated a significant improvement in nerve regeneration, decreased nerve pain and less inflammation with a faster recovery after surgical procedures [4]-[10]. We have previously published data showing NeuroGen can reduce pillar pain and reduce number of pain medications required after endoscopic carpal tunnel release [11].

The Boston carpal tunnel questionnaire (BCTQ) is a common patient rated outcome assessment given to patients undergoing treatment for carpal tunnel syndrome (Appendix A). This assessment consists of 11 items for symptoms and 8 items for function. The minimally important difference in change of score from pre-operative to post-operative has been identified as a 1.14 change in symptoms score and a 0.74 change in function score [12]. Most procedures for carpal tunnel surgery fail to reach this amount of improvement within the first 2 weeks [13] [14] [15]. Several studies evaluating the use of supplements such as alpha lipoic acid, acetyl 1 carnitine and vitamin D on symptoms of carpal tunnel syndrome have used the BCTQ as a patient rated outcome questionnaire [4] [5] [6]. Other studies have evaluated the effect of supplements on the postoperative recovery after carpal tunnel surgery using the BCTQ as an outcome [8] [9]. None of these previous studies have used a comprehensive formula including several ingredients known to promote nerve healing such as NeuroGen. The goal of this study was to evaluate the effectiveness of the nerve supplement NeuroGen on the patient rated outcomes after endoscopic carpal tunnel surgery using the Boston carpal tunnel questionnaire.

\section{Methods}

Patients were seen in our clinic at the Fitzmaurice hand institute over a 5-month period in 2014. All patients had carpal tunnel syndrome based on clinical exam, history, and positive diagnostic findings on nerve conduction studies. All patients failed conservative treatment which included NSAIDS, steroids injections, or splints. 64 Patients were then scheduled for endoscopic carpal tunnel release surgery. They were given the option of using a nerve support supplement to improve outcomes and the recovery after the carpal tunnel surgery. 18 patients chose to have the NeuroGen supplement and there were 46 patients who did not have the supplement in the control group. The supplement was taken for 5 days before surgery and continued for 3 weeks after the surgery. The NeuroGen supplement consisted of 6 tablets a day containing various ingredients proven to improve nerve function, decreased nerve pain and improve recovery after surgery. These ingredients include Methylcobalamin, Acetyl 1 Carnitine, Alpha lipoic acid, N Acetylcysteine, curcumin, benfotiamine, COQ10, bromelain, and 
Serratiopeptidase. Patients were evaluated before surgery with the Boston carpal tunnel questionnaire (BCTQ) both pre-operatively and again at first follow up approximately at 2 weeks. The BCTQ was chosen as it is one of the standard patient rated outcome questionnaires to measure outcomes after carpal tunnel surgery procedures. Statical analysis of the data was performed using a paired t-test with XLSTAT software.

\section{Results}

All 64 patients had the same endoscopic carpal tunnel release performed. None of the patients required conversion to an open procedure or had any intraoperative complications. The follow up evaluation was performed an average of 14 days after surgery. Both the control group and the NeuroGen group demonstrated a statically significant improvement in BCTQ at first follow up in both symptoms and function $(\mathrm{p}<0.005)$. Symptom improvement included less hand or wrist pain during day and at night, less numbness, less weakness, and less difficulty grasping and using small objects. Function improvement included ability to write, button clothes, opening of jars, holding a book, household chores, carrying a grocery basket, bathing and dressing and gripping a telephone. There was a statically significant difference in post-operative BCTQ score with those using the NeuroGen nerve supplement compared to the control group at first follow up visit $(\mathrm{p}<0.005)$ demonstrating a greater improvement in BCTQ with the supplement group (Figure 1) in both symptom and function improvement. The change in score was 1.51 in symptoms and 0.98 change in function from pre-operative score to follow up at 14 days with the NeuroGen group and a change of 0.98 in symptoms and 0.38 in function score in the group without the supplement.

\section{Discussion}

Several dietary supplements have been used to help improve nerve function and reduce nerve symptoms of nerve dysfunction such as neuropathy and crush syndromes. Alpha lipoic acid is a supplement that has been used in previous studies to reduce pillar pain after carpal tunnel surgery [8]. Other studies have demonstrated that when taken before and continued after surgery for 2 months after surgery, Alpha lipoic acid can also improve clinical and neurophysiological outcomes based on nerve conduction studies [9]. Alpha lipoic acid has also been combined with other ingredients such as curcumin and B vitamins taken before and continued for 3 months after surgery with improved sleep and clinical findings compared to the group without the supplement [10].

Alpha lipoic acid has also been used to treat symptoms of carpal tunnel syndrome without surgery. Alpha lipoic acid was combined with gamma-linolenic acid with significant improvement in patients with early CTS [4]. Acetyl 1 carnitine is another supplement which has been used to treat patients with mild and moderate carpal tunnel syndrome. After 4 months of treatment there was a 
1.6

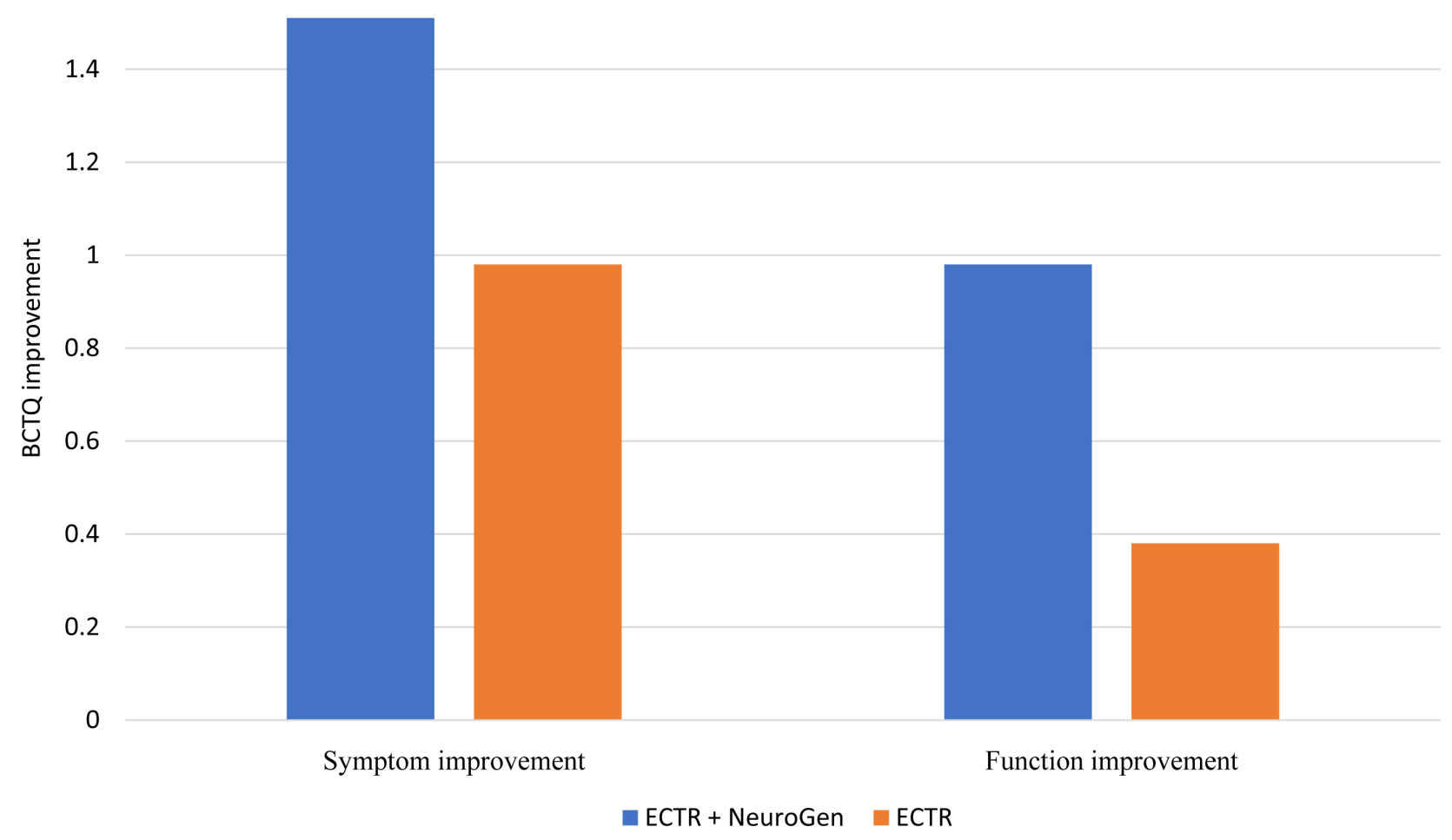

Figure 1. Improvement in symptoms and function after ECTR.

significant improvement in nerve function based on nerve studies, patient rated outcomes of symptoms and function and reduced pain [5]. A review of Vitamin $\mathrm{D}$ for treatment of carpal tunnel syndrome demonstrated that supplementation with Vitamin D for at least 12 weeks could provide favorable improvement with improved nerve function on nerve studies for patients with mild-moderate carpal tunnel syndrome [6]. A study was conducted on serratiopeptidase for patients with carpal tunnel syndrome. $65 \%$ of the patients demonstrated significant improvement on both clinical evaluation and nerve function based on nerve studies at 6 weeks [7].

A nutraceutical consisting of alpha lipoic acid, acetyl 1 carnitine, curcumin, and B complex vitamins were given to a group who received therapy for carpal tunnel syndrome and compared to a placebo and therapy group. After therapy both groups demonstrated clinical improvement, however at 3 months after therapy had ended, only the nutraceutical group maintained this improvement [16]. Another combination study used acetyl 1 carnitine, alpha lipoic acid, quercetin, bromelain, pantothenic acid along with $\mathrm{b}$ complex vitamins for 30 days along with physical therapy (20 days) for treatment of patients with early carpal tunnel syndrome and compared to physical therapy without the supplements [17]. They demonstrated continued improvement in nerve function based on nerve studies at 30 and 60 days along with improved sleep in both groups, however there was a significant greater improvement in the supplement group.

NeuroGen is a unique nerve supplement formula designed to enhance nerve 
recovery and minimize post-operative inflammation and pain. The ingredients have demonstrated significant improvement in nerve regeneration, decreased nerve pain, improved neural mitochondrial function, neuroprotection and decreased inflammatory response. Methylcobalamin, Acetyl-L-Carnitine, N-Acetyl Cysteine, Vitamin D, and Curcumin improve nerve regeneration in several conditions including nerve injuries (crush), nerve repair after transection and neuropathic conditions such as diabetes [18]-[54]. Bromelain, and Serratopeptidase decrease the inflammatory response and have demonstrated improved recovery after surgery with less pain and earlier return to activity [55]-[68]. NeuroGen was recently given to patients after endoscopic carpal tunnel release to evaluate pillar pain after surgery. There was a significant decrease in pain and reduced number of pain medications needed after surgery compared to the group without the supplement [11].

The minimally important difference in BCTQ scores has been reported to be a 1.14 change in symptoms score and a 0.74 change in function score [12]. That study evaluated patients at 3 months post operatively and our study had demonstrated a greater improvement in the BCTQ score by 2 weeks ( 1.51 improvement in symptoms score and 0.98 improvement in function score). Most studies fail to demonstrate a clinically important and significant change in outcome scores within 2 weeks and usually require 6 - 12 weeks to obtain a minimally important change [13] [14] [15]. This study demonstrated that patients who took the nerve support supplement NeuroGen had a significant improvement in reducing symptoms and improving function compared to a group who did not take the supplement after endoscopic carpal tunnel release within 2 week follow up. This improvement in BCTQ score using the NeuroGen formula is significantly better at 2-weeks after surgical release than previous studies evaluating only a single ingredient such as alpha lipoic acid, acetyl 1 carnitine or vitamin D [4] [5] [6] [8] [9].

Limitations of the study include a short follow up period. We chose to focus on the immediate post-operative period and a 2 week follow up to assess the ability of the nerve supplement to decrease the recovery period and subsequently allow patients a faster return to activity. We are evaluating some future studies to include a longer follow up to assess long term improvement using the nerve supplement.

\section{Conclusion}

Our study is consistent with other authors who have demonstrated improvement after carpal tunnel surgery with various supplements that improve nerve function after injury or decompression surgery. Our study is unique in that it contains a combination of several of these nutraceuticals which appears to provide a greater improvement than individual ingredients. The unique formula in NeuroGen provides greater relief of symptoms and improved function based on the carpal tunnel questionnaire after endoscopic carpal tunnel release within a 2-week follow up period. 


\section{Conflicts of Interest}

The author declares no conflicts of interest regarding the publication of this paper.

\section{References}

[1] Atroshi, I., Gummesson, C., Johnsson, R., Ornstein, E., Ranstam, J. and Rosén, I. (1999) Prevalence of Carpal Tunnel Syndrome in a General Population. JAMA, 282, 153-158. https://doi.org/10.1001/jama.282.2.153

[2] Pourmemari, M., Heliövaara, M., Viikari-Juntura, E. and Shiri, R. (2018) Carpal Tunnel Release: Lifetime Prevalence, Annual Incidence, and Risk Factors. Muscle Nerve, 58, 497-502. https://doi.org/10.1002/mus.26145

[3] Kohanzadeh, S., Herrera, F.A. and Dobke, M. (2012) Outcomes of Open and Endoscopic Carpal Tunnel Release: A Meta-Analysis. Hand (NY), 7, 247-251. https://doi.org/10.1007/s11552-012-9413-5

[4] Geronimo, G.D., Caccese, A.F., Caruso, L., Soldati, A. and Passaretti, U. (2009) Treatment of Carpal Tunnel Syndrome with Alpha-Lipoic Acid. European Review for Medical and Pharmacological Sciences, 13, 133-139.

[5] Cruccu, G., Stefano, G.D., Fattaposta, F., Jann, S., Padua, L., Schenone, A. and Truini, A. (2017) L-Acetyl-carnitine in Patients with Carpal Tunnel Syndrome: Effects on Nerve Protection, Hand Function and Pain. CNS Drugs, 31, 665. https://doi.org/10.1007/s40263-017-0476-2

[6] Anusitviwat, C., Suwanno, P. and Suwannaphisit, S. (2021) The Effects of Vitamin D Supplementation in Carpal Tunnel Syndrome Treatment Outcomes: A Systematic Review. Journal of Experimental Orthopaedics, 8, 73. https://doi.org/10.1186/s40634-021-00393-4

[7] Panagariya, A. and Sharma, A.K. (1999) A Preliminary Trial of Serratiopeptidase in Patients with Carpal Tunnel Syndrome. The Journal of the Association of Physicians of India, 47, 1170-1172.

[8] Boriani, F., et al. (2017) Alpha-Lipoic Acid after Median Nerve Decompression at the Carpal Tunnel: A Randomized Controlled Trial. The Journal of Hand Surgery, 42, 236-242.

[9] Guízar, E.A.M., Benavides, L.G., Plascencia, A.R.A., González, S.P., Sutto, S.E.T., Muñoz, E.G.C. and Villar, M.M.-D. (2018) Effect of Alpha-Lipoic Acid on Clinical and Neurophysiologic Recovery of Carpal Tunnel Syndrome: A Double-Blind, Randomized Clinical Trial. Journal of Medicinal Food, 21, 521-526.

[10] Pajardi, G., Bortot, P., Ponti, V. and Novelli, C. (2014) Clinical Usefulness of Oral Supplementation with Alpha-Lipoic Acid, Curcumin Phytosome, and B-Group Vitamins in Patients with Carpal Tunnel Syndrome Undergoing Surgical Treatment. Evidence-Based Complementary and Alternative Medicine, 2014, Article ID: 891310. https://doi.org/10.1155/2014/891310

[11] Fitzmaurice, M.J. (2013) The Effect of NeuroGen ${ }^{\circledR}$ Nerve Support Supplement on Pillar Pain after Endoscopic Carpal Tunnel Release. Modern Plastic Surgery, 4, 5-10. https://doi.org/10.4236/mps.2014.41002

[12] Kim, J.K. and Jeon, S.H. (2013) Minimal Clinically Important Differences in the Carpal Tunnel Questionnaire after Carpal Tunnel Release. Journal of Hand Surgery (European Volume), 38, 75-79. https://doi.org/10.1177/1753193412442137

[13] Trumble, T.E., Diao, E., Abrams, R.A. and Gilbert-Anderson, M.M. (2002) Single- 
Portal Endoscopic Carpal Tunnel Release Compared with Open Release: A Prospective, Randomized Trial. The Journal of Bone and Joint Surgery, 84, 1107-1115. https://doi.org/10.2106/00004623-200207000-00003

[14] Cresswell, T.R., Heras-Palou, C., Bradley, M.J., Chamberlain, S.T., Hartley, R.H., Dias, J.J. and Burke, F.D. (2008) Long-Term Outcome after Carpal Tunnel Decompression-A Prospective Randomised Study of the Indiana Tome and a Standard Limited Palmar Incision. Journal of Hand Surgery (European Volume), 33, 332-336. https://doi.org/10.1177/1753193408090104

[15] Mack, E.M., Callinan, N.J., Reams, M., Bohn, D.C. and Chmielewski, T.L. (2017) Patient-Reported Outcomes after Open Carpal Tunnel Release Using a Standard Protocol with 1 Hand Therapy Visit. Journal of Hand Therapy, 30, 58-64.

https://doi.org/10.1016/j.jht.2016.03.007

[16] Paulucci, T., Piccinini, G., Nusca, S.M., Marsilli, G., Mannocci, A., Torre, G.L., Saraceni, V.M. and Villani, C. (2018) Efficacy of Dietary Supplement with Nutraceutical Composed Combined with Extremely-Low-Frequency Electromagnetic Fields in Carpal Tunnel Syndrome. The Journal of Physical Therapy Science, 30, 777-784. https://doi.org/10.1589/jpts.30.777

[17] Marvulli, R., Ianieri, G., Devenuto, G., Falcicchio, M., Gallo, G.A., Mennuni, C., Gallone, M.F., Fiore, P., Maurizio, R. and Megna, M. (2020) Electrophysiological and Clinical Improvement in Non-Invasive Treatment of Carpal Tunnel Syndrome. Endocrine, Metabolic \& Immune Disorders-Drug Targets, 21, 345-351. https://doi.org/10.2174/1871530320666200728152953

[18] Morani, A.S. and Bodhankar, S.L. (2010) Early Co-Administration of Vitamin E Acetate and Methylcobalamin Improves Thermal Hyperalgesia and Motor Nerve Conduction Velocity Following Sciatic Nerve Crush Injury in Rats. Pharmacological Reports, 62, 405-409. https://doi.org/10.1016/S1734-1140(10)70281-4

[19] Kong, X., Sun, X. and Zhang, J. (2004) The Protective Role of Mecobalamin Following Optic Nerve Crush in Adult Rats. Eye Science, 20, 171-177.

[20] Mikhailov, V.V. and Avakumov, V.M. (1983) Mechanism of the Effect of Methylcobalamin on the Recovery of Neuromuscular Functions in Mechanical and Toxin Denervation. Farmakologiia i Toksikologiia, 46, 9-12.

[21] Okada, K., Tanaka, H., Temporin, K., Okamoto, M., Kuroda, Y., Moritomo, H., Murase, T. and Yoshikawa, H. (2010) Methylcobalamin Increases Erk1/2 and Akt Activities through the Methylation Cycle and Promotes Nerve Regeneration in a Rat Sciatic Nerve Injury Model. Experimental Neurology, 222, 191-203. https://doi.org/10.1016/j.expneurol.2009.12.017

[22] Yamatsu, K., Kaneko, T., Kitahara, A. and Ohkawa, I. (1976) Pharmacological Studies on Degeneration and Regeneration of Peripheral Nerves. (1) Effects of Methylcobalamin and Cobamide on EMG Patterns and Loss of Muscle Weight in Rats with Crushed Sciatic Nerve. Nippon Yakurigaku Zasshi. Folia Pharmacologica Japonica, 72, 259-268. https://doi.org/10.1254/fpj.72.259

[23] Watanabe, T., Kaji, R., Oka, N., Bara, W. and Kimura, J. (1994) Ultra-High Dose Methylcobalamin Promotes Nerve Regeneration in Experimental Acrylamide Neuropathy. Journal of the Neurological Sciences, 122, 140-143. https://doi.org/10.1016/0022-510X(94)90290-9

[24] Yamazaki, K., Oda, K., Endo, C., Kikuchi, T. and Wakabayashi, T. (1994) Methylcobalamin (methyl-B12) Promotes Regeneration of Motor Nerve Terminals Degenerating in Anterior Gracile Muscle of Gracile Axonal Dystrophy (GAD) Mutant Mouse. Neuroscience Letters, 170, 195-197.

https://doi.org/10.1016/0304-3940(94)90272-0 
[25] Liao, W.C., Chen, J.R., Wang, Y.J. and Tseng, G.F. (2010) Methylcobalamin, But Not Methylprednisolone or Pleiotrophin, Accelerates the Recovery of Rat Biceps after Ulnar to Musculocutaneous Nerve Transfer. Neuroscience, 171, 934-949. https://doi.org/10.1016/j.neuroscience.2010.09.036

[26] Sima, A.A.F., Calvani, M., Mehra, M., Amato, A. and Group A-L-C S (2005) AcetylL-Carnitine Improves Pain, Nerve Regeneration, and Vibratory Perception in Patients with Chronic Diabetic Neuropathy: An Analysis of Two Randomized Placebo-Controlled Trials. Diabetes Care, 28, 89-94. https://doi.org/10.2337/diacare.28.1.89

[27] Angelis, C.D., Scarfò, C., Falcinelli, M., Perna, E., Reda, E., Ramacci, M.T. and Angelucci, L. (1994) Acetyl-L-carnitine Prevents Age-Dependent Structural Alterations in Rat Peripheral Nerves and Promotes Regeneration Following Sciatic Nerve Injury in Young and Senescent Rats. Experimental Neurology, 128, 103-114. https://doi.org/10.1006/exnr.1994.1117

[28] Kokkalis, Z.T., Soucacos, P.N. and Terzis, J.K. (2009) Effect of acetyl-L-carnitine on Axonal Sprouting Following Donor Nerve Injury Distal to an End-to-Side Neurorrhaphy Model. Journal of Reconstructive Microsurgery, 25, 483-495. https://doi.org/10.1055/s-0029-1234027

[29] Angelis, C.D., Scarfò, C., Falcinelli, M., Reda, E., Ramacci, M.T. and Angelucci, L. (1992) Levocarnitine Acetyl Stimulates Peripheral Nerve Regeneration and Neuromuscular Junction Remodelling Following Sciatic Nerve Injury. International Journal of Clinical Pharmacology Research, 12, 269-279.

[30] Fernandez, E., Pallini, R., Lauretti, L., Marchese, E., Bozzini, V., Sbriccoli, A. and Rossi, G.F. (1991) Levocarnitine Acetyl Promotes the Regeneration of Peripheral Sensory Axons and Reduces the Hypertrophy of Axotomized Spinal Cord Motoneurons in Rats. Drugs under Experimental and Clinical Research, 17, 563-570.

[31] Hart, A.M., Wiberg, M. and Terenghi, G. (2002) Pharmacological Enhancement of Peripheral Nerve Regeneration in the Rat by Systemic Acetyl-L-carnitine Treatment. Neuroscience Letters, 334, 181-185. https://doi.org/10.1016/S0304-3940(02)00982-5

[32] Wilson, A.D.H., Hart, A., Wiberg, M. and Terenghi, G. (2010) Acetyl-l-carnitine Increases Nerve Regeneration and Target Organ Reinnervation-A Morphological Study. Journal of Plastic, Reconstructive \& Aesthetic Surgery. JPRAS, 63, 11861195. https://doi.org/10.1016/j.bjps.2009.05.039

[33] Karsidag, S., Akcal, A., Sahin, S., Kabukcuoglu, F. and Ugurlu, K. (2012) Neurophysiological and Morphological Responses to Treatment with Acetyl-L-carnitine in a Sciatic Nerve Injury Model: Preliminary Data. The Journal of Hand Surgery (European Volume), 37, 529-536. https://doi.org/10.1177/1753193411426969

[34] Wilson, A.D.H., Hart, A., Brännström, T., Wiberg, M. and Terenghi, G. (2003) Primary Sensory Neuronal Rescue with Systemic Acetyl-L-carnitine Following Peripheral Axotomy. A Dose-Response Analysis. British Journal of Plastic Surgery, 56, 732-739. https://doi.org/10.1016/j.bjps.2003.08.005

[35] Fernandez, E., Pallini, R., Gangitano, C., Fá, A.D., Sangiacomo, C.O., Sbriccoli, A., Ricoy, J.R. and Rossi, G.F. (1989) Effects of L-carnitine, L-acetylcarnitine and Gangliosides on the Regeneration of the Transected Sciatic Nerve in Rats. Neurological Research, 11, 57-62. https://doi.org/10.1080/01616412.1989.11739863

[36] Hart, A.M., Wiberg, M., Youle, M. and Terenghi, G. (2002) Systemic Acetyl-L-Carnitine Eliminates Sensory Neuronal Loss after Peripheral Axotomy: A New Clinical Approach in the Management of Peripheral Nerve Trauma. Experimental Brain Research. Experimentelle Hirnforschung. Expérimentation cérébrale, 145, 182-189. https://doi.org/10.1007/s00221-002-1100-2 
[37] Kostopoulos, V.K., Davis, C.L. and Terzis, J.K. (2009) Effects of acetylo-L-carnitine in End-to-Side Neurorrhaphy: A Pilot Study. Microsurgery, 29, 456-463. https://doi.org/10.1002/micr.20639

[38] Terenghi, G., Hart, A. and Wiberg, M. (2011) The Nerve Injury and the Dying Neurons: Diagnosis and Prevention. Journal of Hand Surgery (European Volume), 36, 730-734. https://doi.org/10.1177/1753193411422202

[39] Fernandez, E., Pallini, R., Gangitano, C., Fá, A.D., Olivieri-Sangiacomo, C., Sbriccoli, A., Ricoy, J. and Rossi, G.F. (1990) Studies on the Degenerative and Regenerative Phenomena Occurring after Transection and Repair of the Sciatic Nerve in Rats: Effects of Acetyl-L-Carnitine. International Journal of Clinical Pharmacology Research, 10, 85-99.

[40] Fernandez, E., Pallini, R., Lauretti, L., Marca, F.L., Scogna, A. and Rossi, G.F. (1997) Motonuclear Changes after Cranial Nerve Injury and Regeneration. Archives italiennes de biologie, 135, 343-351.

[41] Simone, R.D., Aloe, L., Ferraris, L. and Ramacci, M.T. (1992) Levocarnitine Acetyl Treatment Promotes Iris Reinnervation Following 6-Hydroxydopamine-Induced Noradrenergic Denervation in Rats. International Journal of Clinical Pharmacology Research, 12, 281-287.

[42] Wilson, A.D.H., Hart, A., Brännström, T., Wiberg, M. and Terenghi, G. (2007) Delayed acetyl-L-carnitine Administration and Its Effect on Sensory Neuronal Rescue after Peripheral Nerve Injury. Journal of Plastic, Reconstructive \& Aesthetic Surgery: JPRAS, 60, 114-118. https://doi.org/10.1016/j.bjps.2006.04.017

[43] Kotil, K., Kirali, M., Eras, M., Bilge, T. and Uzun, H. (2007) Neuroprotective Effects of acetyl-L-carnithine in Experimental Chronic Compression Neuropathy. A Prospective, Randomized and Placebo-Control Trials. Turkish Neurosurgery, 17, 67-77.

[44] Fernandez, E., Pallini, R., Lauretti, L., Marchese, E., Gangitano, C., Fá, A.D., Olivieri-Sangiacomo, C., Sbriccoli, A. and Rossi, G.F. (1992) Levocarnitine Acetyl Prevents Cell Death Following Long-Term Section of the Vagus Nerve in Rats. International Journal of Clinical Pharmacology Research, 12, 289-297.

[45] Love, A., Cotter, M.A. and Cameron, N.E. (1996) Effects of the Sulphydryl Donor N-acetyl-L-cysteine on Nerve Conduction, Perfusion, Maturation and Regeneration Following Freeze Damage in Diabetic Rats. European Journal of Clinical Investigation, 26, 698-706. https://doi.org/10.1111/j.1365-2362.1996.tb02156.x

[46] Welin, D., Novikova, L.N., Wiberg, M., Kellerth, J.-O. and Novikov, L.N. (2009) Effects of N-acetyl-cysteine on the Survival and Regeneration of Sural Sensory Neurons in Adult Rats. Brain Research, 1287, 58-66.

https://doi.org/10.1016/j.brainres.2009.06.038

[47] Karlidag, T., Yildiz, M., Yalcin, S., Colakoglu, N., Kaygusuz, I. and Sapmaz, E. (2012) Evaluation of the Effect of Methylprednisolone and N-acetylcystein on Anastomotic Degeneration and Regeneraton of the Facial Nerve. Auris Nasus Larynx, 39, 145-150. https://doi.org/10.1016/j.anl.2011.03.004

[48] Brown, J., Bianco, J.I., McGrath, J.J. and Eyles, D.W. (2003) 1,25-dihydroxyvitamin D3 Induces Nerve Growth Factor, Promotes Neurite Outgrowth and Inhibits Mitosis in Embryonic Rat Hippocampal Neurons. Neuroscience Letters, 343, 139-143. https://doi.org/10.1016/S0304-3940(03)00303-3

[49] Fukuoka, M., Sakurai, K., Ohta, T., Kiyoki, M. and Katayama, I. (2001) Tacalcitol, an Active Vitamin D3, Induces Nerve Growth Factor Production in Human Epidermal Keratinocytes. Skin Pharmacology and Applied Skin Physiology, 14, 226-233. https://doi.org/10.1159/000056351 
[50] Chabas, J.-F., Alluin, O., Rao, G., Garcia, S., Lavaut, M.-N., Risso, J.J., Legre, R., Magalon, G., Khrestchatisky, M., Marqueste, T., Decherchi, P. and Feron, F. (2008) Vitamin D2 Potentiates Axon Regeneration. Journal of Neurotrauma, 25, 1247-1256. https://doi.org/10.1089/neu.2008.0593

[51] Javan, M.G.M.F., Mirnajafi-Zadeh, J.J.M.F., Mozafari, S.M.-Z.J.F., Tiraihi, T.M.S.F. and Tiraihi, T. (2010) Vitamins E and D3 Attenuate Demyelination and Potentiate Remyelination Processes of Hippocampal Formation of Rats Following Local Injection of Ethidium Bromide. Cellular and Molecular Neurobiology, 30, 289-299.

[52] Xu, Y., Ku, B., Cui, L., Li, X., Barish, P.A., Foster, T.C. and Ogle, W.O. (2007) Curcumin Reverses Impaired Hippocampal Neurogenesis and Increases Serotonin Receptor 1A mRNA and Brain-Derived Neurotrophic Factor Expression in Chronically Stressed Rats. Brain Research, 1162, 9-18.

https://doi.org/10.1016/j.brainres.2007.05.071

[53] Liao, K.-K., Wu, M.-J., Chen, P.-Y., Huang, S.-W., Chiu, S.-J., Ho, C.-T. and Yen, J.-H. (2012) Curcuminoids Promote Neurite Outgrowth in PC12 Cells through MAPK/ERK- and PKC-Dependent Pathways. Journal of Agricultural and Food Chemistry, 60, 433-443. https://doi.org/10.1021/jf203290r

[54] Kandhare, A.D., Raygude, K.S., Ghosh, P., Ghule, A.E. and Bodhankar, S.L. (2012) Therapeutic Role of Curcumin in Prevention of Biochemical and Behavioral Aberration Induced by Alcoholic Neuropathy in Laboratory Animals Neuroscience Letters, 511, 18-22. https://doi.org/10.1016/j.neulet.2012.01.019

[55] Fitzhugh, D.J., Shan, S., Dewhirst, M.W. and Hale, L.P. (2008) Bromelain Treatment Decreases Neutrophil Migration to Sites of Inflammation. Clinical Immunology (Orlando, Fla.), 128, 5411-5419. https://doi.org/10.1016/j.clim.2008.02.015

[56] Gaspani, L., Limiroli, E., Ferrario, P. and Bianchi, M. (2002) In Vivo and in Vitro Effects of Bromelain on PGE(2) and SP Concentrations in the Inflammatory Exudate in Rats. Pharmacology, 65, 83-86. https://doi.org/10.1159/000056191

[57] Hale, L.P., Chichlowski, M., Trinh, C.T. and Greer, P.K. (2010) Dietary Supplementation with Fresh Pineapple Juice Decreases Inflammation and Colonic Neoplasia in IL-10-Deficient Mice with Colitis. Inflammatory Bowel Diseases, 16, 2012 2021. https://doi.org/10.1002/ibd.21320

[58] Muller, S., Marz, R., Schmolz, M., Drewelow, B., Eschmann, K. and Meiser, P. (2012) Placebo-Controlled Randomized Clinical Trial on the Immunomodulating Activities of Low- and High-Dose Bromelain after Oral Administration-New Evidence on the Antiinflammatory Mode of Action of Bromelain. Phytotherapy Research, 27, 199-204. https://doi.org/10.1002/ptr.4678

[59] Inchingolo, F., Tatullo, M., Marrelli, M., Inchingolo, A.M., Picciariello, V., Inchingolo, A.D., Dipalma, G., Vermesan, D. and Cagiano, R. (2010) Clinical Trial with Bromelain in Third Molar Exodontia. European Review for Medical and Pharmacological Sciences, 14, 771-774.

[60] Masson, M. (1995) Bromelain in Blunt Injuries of the Locomotor System. A Study of Observed Applications in General Practice. Fortschritte der Medizin, 113, 303-306.

[61] Jadav, S., Patel, N., Shah, T., Gajera, M., Trivedi, H. and Shah, B. (2010) Comparison of Anti-Inflammatory Activity of Serratiopeptidase and Diclofenac in Albino Rats. Journal of Pharmacology and Pharmacotherapeutics, 1, 116-117. https://doi.org/10.4103/0976-500X.72362

[62] Swamy, A.H.M.V. and Patil, P.A. (2008) Effect of Some Clinically Used Proteolytic Enzymes on Inflammation in Rats. Indian Journal of Pharmaceutical Sciences, 70, 114-117. https://doi.org/10.4103/0250-474X.40347 
[63] Mazzone, A., Catalani, M., Costanzo, M., Drusian, A., Mandoli, A., Russo, S., Guarini, E. and Vesperini, G. (1990) Evaluation of Serratia Peptidase in Acute or Chronic Inflammation of Otorhinolaryngology Pathology: A Multicentre, DoubleBlind, Randomized Trial versus Placebo. The Journal of International Medical Research, 18, 379-388. https://doi.org/10.1177/030006059001800506

[64] Al-Khateeb, T.H. and Nusair, Y. (2008) Effect of the Proteolytic Enzyme Serrapeptase on Swelling, Pain and Trismus after Surgical Extraction of Mandibular Third Molars. International Journal of Oral and Maxillofacial Surgery, 37, 264-268. https://doi.org/10.1016/j.ijom.2007.11.011

[65] Esch, P.M., Gerngross, H. and Fabian, A. (1989) Reduction of Postoperative Swelling. Objective Measurement of Swelling of the Upper Ankle Joint in Treatment with Serrapeptase-A Prospective Study. Fortschritte der Medizin, 107, 67-68, 71-72.

[66] Tachibana, M., Mizukoshi, O., Harada, Y., Kawamoto, K. and Nakai, Y. (1984) A Multi-Centre, Double-Blind Study of Serrapeptase versus Placebo in Post-Antrotomy Buccal Swelling. Pharmatherapeutica, 3, 526-530.

[67] Bhoobalakrishnan, M.S., Rattan, V., Rai, S., Jolly, S.S. and Malhotra, S. (2021) Comparison of Efficacy and Safety of Bromelain with Diclofenac Sodium in the Management of Postoperative Pain and Swelling Following Mandibular Third Molar Surgery. Advances in Oral and Maxillofacial Surgery, 3, Article ID: 100112. https://doi.org/10.1016/j.adoms.2021.100112

[68] Majid, O.W. and Al-Mashhadani, B.A. (2014) Perioperative Bromelain Reduces Pain and Swelling and Improves Quality of Life Measures after Mandibular Third Molar Surgery: A Randomized, Double-Blind, Placebo-Controlled Clinical Trial. Journal of Oral and Maxillofacial Surgery, 72, 1043-1048. https://doi.org/10.1016/j.joms.2013.12.035 


\section{Appendix A}

\section{Boston Carpal Tunnel Syndrome Questionnaire (BCTQ)}

\section{(1) Symptom severity scale (11 items)}

\begin{tabular}{|c|c|c|c|c|c|}
\hline & 1 & 2 & 3 & 4 & 5 \\
\hline $\begin{array}{l}\text { 1. How severe is the hand or wrist pain that you have at } \\
\text { night? }\end{array}$ & Normal & Slight & Medium & Severe & Very serious \\
\hline $\begin{array}{l}\text { 2. How often did hand or wrist pain wake you up during a } \\
\text { typical night in the past two weeks? }\end{array}$ & Normal & Once & 2 to 3 times & 4 to 5 times & $\begin{array}{l}\text { More than } 5 \\
\text { times }\end{array}$ \\
\hline $\begin{array}{l}\text { 3. Do you typically have pain in your hand or wrist during } \\
\text { the daytime? }\end{array}$ & No pain & Slight & Medium & Severe & Very serious \\
\hline $\begin{array}{l}\text { 4. How often do you have hand or wrist pain during } \\
\text { daytime? }\end{array}$ & Normal & $1-2$ times / day & 3-5 times / day & $\begin{array}{l}\text { More than } 5 \\
\text { times }\end{array}$ & Continued \\
\hline $\begin{array}{l}\text { 5. How long on average does an episode of pain last during } \\
\text { the daytime? }\end{array}$ & Normal & $<10$ minutes & 10 60 Continued & $>60$ minutes & Continued \\
\hline 6. Do you have numbness (loss of sensation) in your hand? & Normal & Slight & Medium & Severe & Very serious \\
\hline 7. Do you have weakness in your hand or wrist? & Normal & Slight & Medium & Severe & Very serious \\
\hline 8. Do you have tingling sensations in your hand? & Normal & Slight & Medium & Severe & Very serious \\
\hline $\begin{array}{l}\text { 9. How severe is numbness (loss of sensation) or tingling at } \\
\text { night? }\end{array}$ & Normal & Slight & Medium & Severe & Very serious \\
\hline $\begin{array}{l}\text { 10. How often did hand numbness or tingling wake you up } \\
\text { during a typical night during the past two weeks? }\end{array}$ & Normal & Once & 2 to 3 times & 4 to 5 times & $\begin{array}{l}\text { More than } 5 \\
\text { times }\end{array}$ \\
\hline $\begin{array}{l}\text { 11. Do you have difficulty with the grasping and use of small } \\
\text { objects such as keys or pens? }\end{array}$ & Without difficulty & Little difficulty & $\begin{array}{l}\text { Moderately } \\
\text { difficulty }\end{array}$ & Very difficulty & Very difficult \\
\hline
\end{tabular}

\section{(2) Functional status scale (8 items) :}

\begin{tabular}{|c|c|c|c|c|c|}
\hline & No difficulty & Little difficulty & Moderate difficulty & Intense difficulty & $\begin{array}{l}\text { Cannot perform the } \\
\text { activity at all due to } \\
\text { hands and wrists } \\
\text { symptoms }\end{array}$ \\
\hline Writing & 1 & 2 & 3 & 4 & 5 \\
\hline Buttoning of clothes & 1 & 2 & 3 & 4 & 5 \\
\hline Holding a book while reading & 1 & 2 & 3 & 4 & 5 \\
\hline Gripping of a telephone handle & 1 & 2 & 3 & 4 & 5 \\
\hline Opening of jars & 1 & 2 & 3 & 4 & 5 \\
\hline Household chores & 1 & 2 & 3 & 4 & 5 \\
\hline Carrying of grocery basket & 1 & 2 & 3 & 4 & 5 \\
\hline Bathing and dressing & 1 & 2 & 3 & 4 & 5 \\
\hline
\end{tabular}

